\title{
Chinese Economic Outlook after Global Crisis
}

\author{
Liang-Xin $\mathbf{L i}^{1}$
}

\begin{abstract}
This paper will demonstrate what china was doing, is doing and will do for its economic expansion during and after global crisis. Many thoughts and theories about Chinese economic reforms are analyzed. The road map and goal of Chinese economic growth are examined and outlined in this paper. How to keep Chinese economy fast growth is this paper's key issue which is thoroughly discussed.
\end{abstract}

JEL classification numbers: E6

Keywords: Chinese economy, high growth, economic reform, competitive, global crisis

\section{Introduction}

Since 2008, the global economy has been experiencing the deepest downturn in the post-World War II period, as the financial crisis rapidly spreads around the world. A large number of advanced economies have fallen into recession, and

${ }^{1}$ Business school, Hunan International Economics University, Changsha 410205, Hunan,China, e-mail: apolo1@sina.com

Article Info: Revised : October 16, 2011. Published online : November 30, 2011 
economies in the rest of the world have slowed abruptly. Global trade and financial flows are shrinking, while output and employment losses mount. Credit markets remain frozen as borrowers are engaged in a drawn-out deleveraging process and banks struggle to improve their financial health.

The recovery is expected to be slow, as financial systems remain impaired, support from public policies will gradually have to be withdrawn, and households in economies that suffered asset price busts will continue to rebuild savings while struggling with high unemployment, the report said.

Table 1: The growth rate for each year of $1978-2008$

\begin{tabular}{llll}
\hline Year & Growth rate & Year & Growth rate \\
\hline & & & \\
\hline 1978 & $11.7 \%$ & 1995 & $10.5 \%$ \\
1979 & $7.6 \%$ & 1996 & $9.6 \%$ \\
1980 & $7.8 \%$ & 1997 & $8.8 \%$ \\
1981 & $5.2 \%$ & 1998 & $7.8 \%$ \\
1982 & $9.1 \%$ & 1999 & $7.1 \%$ \\
1983 & $10.9 \%$ & 2000 & $8.0 \%$ \\
1984 & $15.2 \%$ & 2001 & $7.5 \%$ \\
1985 & $13.5 \%$ & 2002 & $8.3 \%$ \\
1986 & $8.8 \%$ & 2003 & $9.5 \%$ \\
1987 & $11.6 \%$ & 2004 & $10.1 \%$ \\
1988 & $11.3 \%$ & 2005 & $10.4 \%$ \\
1989 & $4.1 \%$ & 2006 & $11.6 \%$ \\
1990 & $3.8 \%$ & 2007 & $13 \%$ \\
1991 & $9.2 \%$ & 2008 & $9 \%$ \\
1992 & $14.2 \%$ & 2009 & $9.1 \%$ \\
1993 & $13.5 \%$ & & \\
1994 & $12.6 \%$ & Average & $9.6 \%$ \\
& & &
\end{tabular}

What China as an important economy entity has done, is doing and will do will have a significant influence to the global economy. This paper will provide all around insights on the following aspects on Chinese economy: global crisis influence; china's response to global crisis; Chinese economy in a long run; 
Chinese economy's fast growth; Chinese economic reforming; China as global economic growth engine. It is my goal to provide broad views on Chinese economy and some thoughts on global economy after global crisis.

\section{The impact of the global crisis on Chinese economy}

Chinese economy growth rate reached the peak in 2007, it starts to slow down since the third quarter of 2007, but keeps a growth rate above $10 \%$. The global crisis's effect emerges since the third quarter of 2008: the fourth quarter's growth rate was just 6.8\%, and decreased to $6.1 \%$ in the first quarter of 2009 .

The global crisis effect to Chinese financial market is small due to the fact that Chinese capital market is not completely open to international funds.

The influence of global crisis to Chinese expert industry is very heavy. Since October 2008, Chinese expert has started to decrease.

The effect of global crisis to Chinese job market is heavy, it produced about 30 million job lose in the first quarter of 2009, mostly due to Chinese export industry sector's huge decrease.

\section{China's responses to the global crisis}

To reduce the effects of global crisis and recover quickly, Chinese government takes many decisive and high efficient procedures to tackle the financial turmoil which include:

A. Implement expansionary monetary policy. Include:

1) lower the deposit reserve rate.

2) lower the interest rate of deposits and loans. 
3) encourage loans.

B. Increase government spending heavily.

The central government made a two year plan to invest 4 trillion RMB. It is equivalent to $16 \%$ of Chinese 2007 GDP. The major goal is pushing for a better housing, peasants' living in rural area; an modernized railway transportation; more environmental protection projects.

C. Take structural reduce of taxes.

This procedure includes medium to small size enterprises and housing industry favorable tax reform.

D. Undertake reform and promotion of industry.

The central government outlined reform and promotion plan for steel, auto, equipments, electronics and information, textile, chemical, oil, color-metal, ship, light-industry, logistics, industry.

As results of these procedures, Chinese economy made a 9.1\% growth in 2009 which is the fastest growing economy in the world after recession. China is eyeing on a double digit growth for 2010. Now all the macro-economic indicators are showing that Chinese economy are shaking off the global crisis influence and runs toward a full swing high growth development.

\section{Chinese economy in a long run}

Since 1978, the free market reform has been the major task of Chinese economy. Since then, Chinese economy keeps growing at a rate around 9.6\% each year for more than 30 years. In order to secure a fast and sustainable development of Chinese economy, China now is taking many important measures to facilitate Chinese economy's growth.

Enhance the ability to lead the sustainable growth. China now is training its governing body and advertising the ideology of the sustainable development to 
build it into its political system, market mechanism, public and enterprises decision procedures.

1 Environmental protection and management are reformed to facilitate the free market requirements.

2 Turn the traditional industry society toward a knowledge-based economy informational society.

3 The international corporation entities and channels are becoming more diversified. China as a WTO member will enjoy as a equal trade partner to corporate with any other members. This will widen china's corporation channels and strongly enhance china’s development opportunities.

\section{Fast grow toward the top of global economy}

How to keep the high growth rate for next 20-30 years is the key issue of any policy making in China. To satisfy this goal, China will take the following steps to realize the modernization of Chinese people's life, include:

1. Industrialization process will be a leading driving force for Chinese economic growth.

A. Regional corporation as a driving force

The regional corporation will take advantages of resources reallocation, production redistribution, position advantage, infrastructure development, raw materials supplies, labor movement in a large scale fashion to stimulate the demands, raise the industrial structure, drive economy fast growth.

B. Industrial structure reshaping as a driving force

China will do the following two things to secure its high growth in industrialization:

1) Strategic industries integration and strengthen 
2) Resource industries development.

C. Financial system modernization as a driving force

China will complete its financial system modernization process, which include: completing the laws for financial system; developing more instruments for the financial market; reducing the government control of the investment and financing; pushing for a global free conversion RMB; participating the international capital flow; building a more efficient and high informational financial system, etc.

2. Urbanization will be a key push for china economic growth

By 2009, china urbanization rate is just $46.6 \%$ 。 To 2030, China will try to reach a goal to put this rate at $65 \%$. In order to realize this goal, China will raise $1 \%$ population each year into the urban living standard.

3. Informationalization will be an important way to speed up Chinese economy. Information technology is the key modernization criteria for every country. How to obtain and use the information is a key issue for all modern life.

1) Information will enhance the efficiency of modern decision making, management, living. Information is a productivity, which leads to high quality growth of economy.

2) To build up Chinese information system will stimulate the demands, speed up Chinese modernization and support china economy growth.

4. Technology is the key factor for Chinese economic growth.

These driving forces will support china economy high growth rate to keep its growth rate above $8 \%$ for next few decades. By 2030, China will be No.1 economy in the world. China already passed Japan as the world No.2 economy earlier this year. The road toward the top is bright and fast though China will have to face many challenges, such as, energy shortage, political reformin, international competitiveness, etc.

As projected, China will pass USA as No.1 economy in the year 2026. 


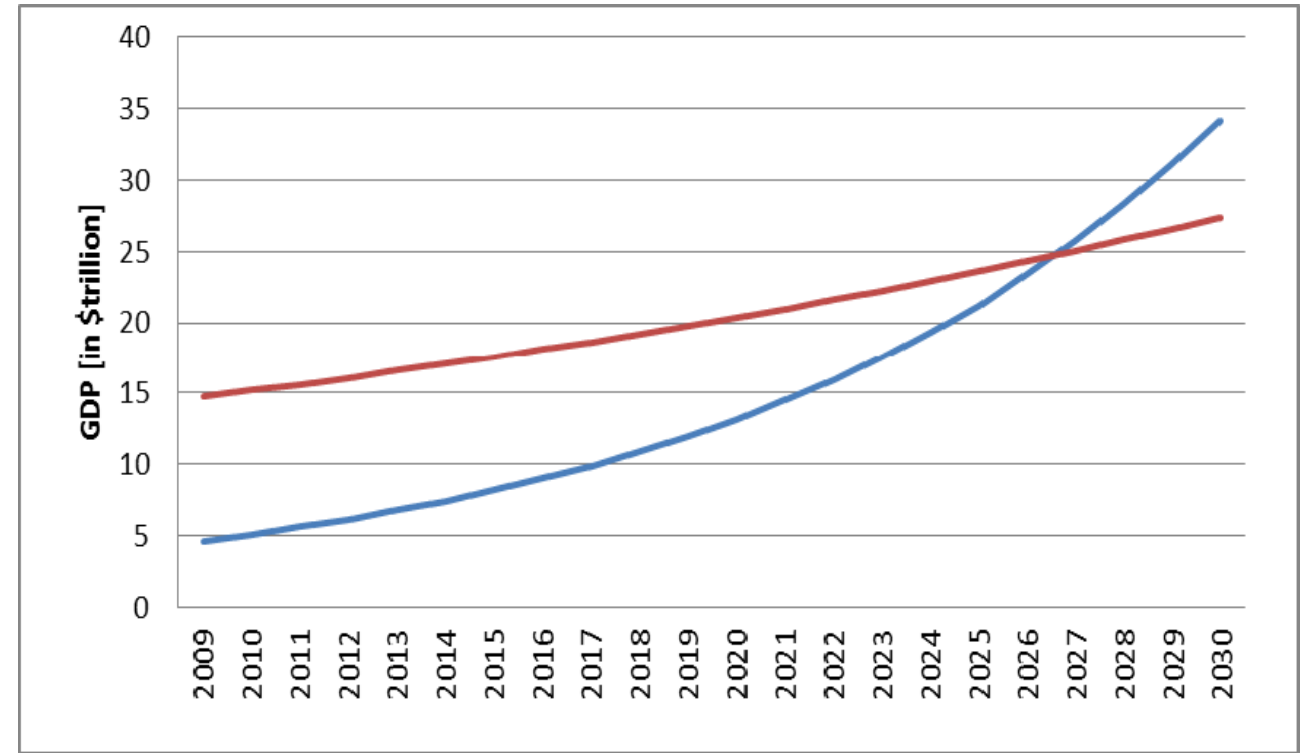

Figure 1: Projected Chinese and USA GDP in the near future. Red line: USA GDP; Blue line: Chinese GDP. The cross point is at the year 2026 .

\section{Chinese economic reforms}

Since 1978, China has undertaken many decisive reformings of its old style political and government-controlled economy.

To guide this historical reform of huge-population long history country, China put its reform emphasis on the following fields:

1) Reform the agriculture economy and rural peasants management;

2) open economy and set up many special economic regions for free market;

3) privatize enterprises and develop other economic systems from free economy;

4) Reform public finance and modernize financial system;

5) Reform price forming mechanism and market system;

6) Reform employment and income distribution and build up an efficient social security system; 
7) Restructure education, science and technology, culture system;

8) Reform health and human services sector.

So far, Chinese reform is a success and a miracle of economy in Chinese and world history. With the guidance of the new theory, China is endeavoring to become a stable, progressive, harmonic nation. It is china's ambitious goal to make its people living in a prosperous and peaceful environment and in the world No.1 economy and innovation center in about 20 years.

\section{Conclusion}

In the long run, China's economic development can be classified as two stages: first, China will try to get all its people a modernized living standard as fast as possible, that is to say, China will be a manufacture center of modern products. I will call this stage the quantitative expansion period. In the second stage, China will expand its market and economy by technology innovation mainly, which I will call it a qualitative expansion stage. At this stage, China will use new technology products to create consumption and keep its people alreadymodernized living standard abreast with the brand new technology frontier. With its largest human resources, China will be able to create more new products if Chinese education, scientific and research systems are effective.

In about 20 years, China will reach the top of the world economy by overtaking USA. But Chinese average individual people's living standard is still 1/4 of USA. China will keep its fast growth for another 20 years and will be the top driving force for world economy. China's modernization is a long and fast process. By finishing this process, China will contribute the world a 1.3 billion good living people and stronger economic growth engine than ever before and any other country in the world history. It is a beautiful thing to see China's run toward its modernization era. 


\section{References}

[1] All data are from Chinese national bureau of statistics.

[2] Liang-Xin Li, Research on the Quantitative Dynamic Structure of Shocks in Macroeconomics Business Cycle, International Journal of Business and Management, 5(6), (2010).

[3] World development report, Tsinghua University Press, 2006.

[4] World economic outlook 2010, International Monetary Fund (IMF).

[5] Chinese 30 years' reform, Published by People's Press, ( $1^{\text {st }}$ ed.), 2008.

[6] Global Financial Stability Report: Financial Stress and Deleveraging-Macro -Financial Implications and Policy (Washington, October), International Monetary Fund (IMF), 2008. 